\title{
Differentiate Patterns of Individually Perceived Quality of Life in Big Cities, Towns and Rural Areas
}

\author{
Egidijus Rybakovas
}

\author{
Kaunas University of Technology \\ K. Donelaicio st. 73, LT-44029, Kaunas, Lithuania \\ E-mail.egidijus.rybakovas@ktu.lt
}

cross $^{\text {ref }}$ http://dx.doi.org/10.5755/j01.ee.27.5.14640

\begin{abstract}
Generally, it is agreed that QoL differs in diverse local places. Explaining these differences remains a complex and challenging problem. Scientific research has concluded that the impacts of socio-economic circumstances in local places (measured by social indicators) on subjectively perceived individual QoL are not direct, but complex, versatile and diverse. Objective differences of socio-economic factors in local places suggest that personal characteristics as well as other objective and subjective QoLfactors, specific to individuals, could form some common patterns, able to disclose the differences in individually perceived QoL in different socio-economic conditions and diverse local places, e.g. cities, towns, or rural areas. The research aims at investigating differences in the patterns of individual subjectively perceived QoL in diverse local places. The differences of the considered local places are reasoned by the indicators of objective socio-economic conditions in cities, towns and rural areas. The tested presumption is that common patterns of individual subjectively perceived QoL differ, respecting objective socioeconomic factors in local places. The research concludes with the discovery and discussion of statistical regression models to predict individual subjectively perceived QoL in towns, big cities and rural areas. Residents' attitude to social environment, their abilities to deal with important problems in life, household total income and age are used as predictors to explain the differences of individual subjectively perceived QoL. The case of Lithuania is being investigated, using European Social Survey (round 6, 2013) data.
\end{abstract}

Keywords: Quality of Life (QoL), Local Place, Social Iindicators, Subjective QoL, Oobjective QoL, Subjective QoL Perception.

\section{Introduction}

"Whilst the natural sciences deal with 'things', the social sciences deal with people who have beliefs, desires, intentions, goals and who are very different from one place to another and from time to time. This makes theories in the social sciences extremely local in scope and dependent on time and space" (Russo, 2009). Individually perceived QoL in a local place is a phenomenon that differs regarding place and time; therefore, it requires investigation, based on the data, describing a local context. It is assumed that the same objective local place-specific factors and conditions are not equally important and they do not have the same value for people, living in different places.

The QoL in a local place concept anticipates that the overall individual subjectively perceived QoL is being determined by a range of factors (Collins, 2013; Diener \& Suh, 1997; Henchoz et al., 2015; McCrea, Shyy, \& Stimson, 2006; Przybyla, Kulczyk-Dynowska, \& Kachniarz, 2014; Pukeliene \& Starkauskiene, 2011; Starkauskiene, 2011; Tomaszewski \& Perales, 2014), including objective external some certain place-specific local living conditions - objective opportunities; objective personal QoL related characteristics, such as average income, education level, or health status (that could be influenced, or even determined, by external factors); subjective individual experience, attitudes and evaluation of local place's external QoL factors and one's own objective personal characteristics; personal factors - socio-demographic characteristics of particular individuals, such as age, gender, etc.
Reasoned by a scientific literature review, the current research problem has been grounded in the expectation that the above-mentioned factors constitute certain subjective QoL perception patterns, specific to a local place. These patterns might be differentiated, based on the importance of certain factors or their groups. The awareness of differentiate QoL perception patterns, dependent on local place characteristics, is crucially important when making decisions to adequately improve regional strategic development.

The relevance and the necessity of this research is being reasoned by the notion of McCrea, Stimson \& Marans (2011) that very often, across different countries, policy statements for the strategic development of a local place are based on the assumption that improvements in the objective socio-economic indicators of $Q o L$ directly relate to improvements in the expected subjective experience of QoL. However, according to McCrea et al. (2011), these statements are made "when little is actually known about the existence and strength and scope of these associations". Often, predictive assumptions that the improvements in objective social indicators of a local place QoL are positively associated with the expected increase in subjective experience are made having little knowledge about these relationships (McCrea et al., 2006).

Most of the QoL in a local place measurement and prediction instruments, meant to support local place QoL management, are constructed as simple indexes, based on weighted average calculations, usually built by selecting a range of sound appropriate and relevant social indicators. Indexes are calculated applying experts' opinion based factor weightings. The averaged index calculation method seems to 
be appropriate for QoL measurement (Pukeliene \& Starkauskiene, 2011; Starkauskiene, 2011), but only when the investigation is limited to the aims of comparison, ratings development and general QoL evaluation. The aggregate index based measurement is also widely used in measuring the competitiveness of regions, countries and other objects (Bruneckiene, Guzavicius, \& Cincikaite, 2010; Bruneckiene, Cincikaite, \& Kilijoniene, 2012). Very often, QoL indicators overlap in the local place and urban competitiveness measurement.

When the application of QoL measurement turns to the idea of building and reasoning a certain local place context specific development strategy, aimed at QoL improvement, the weighted indexes which compare several investigated places (i.e. cities, municipalities regions, or even states) are not sufficient. Weighted index based QoL measurements do not provide information about empirically observed (not experts' subjective opinion based) relationships among objective local place living conditions and other objective and subjective personal factors as well as respective subjective individual QoL perceptions.

The statistical probability based modelling of the expected impacts and changes of individual subjectively perceived QoL in a local place is problematic, because objective local place-specific factors are measured at the macro level, whereas individual subjective QoL perceptions are always observed personally, at the micro individual level (Collins, 2013; McCrea et al., 2006). To predict individual subjectively perceived QoL which is related to the local place of living, both macro level data as well as questionnaire survey (micro level) data have to be used (Akranaviciūte \& Ruzevicius, 2007; Diener \& Suh, 1997; Malkina-Pykh \& Pykh, 2008; Pukeliene \& Starkauskiene, 2011; Starkauskiene, 2011; Uysal, Sirgy, Woo, \& Kim, 2016).

The solutions to overcome this challenge (further explored in this article) could be reached by investigating the differences of individual QoL perception patterns, inherent in different socio-economic settings. Since these selected settings are associated with certain objective external factors, described by common social indicators, it should be possible to forecast individual subjective QoL under these specific and different local conditions.

The aim of the research is to reveal empirically observed differentiate patterns of individual subjectively perceived QoL, present in different socio-economic settings of big cities, towns and rural areas, based on individual subjective and objective QoL factors. The aim is to be achieved by completing three objectives:

1) to develop a conceptual model of the expected relationships among personal objective and subjective QoL factors as the predictors of individual subjectively perceived QoL in local places;

2) to operationalize the model by selecting personal objective and subjective QoL factors, observed in Lithuanian cities, towns and rural areas;

3) to find linear regression models, describing the observed relationships among personal objective and subjective QoL factors and individually perceived subjective QoL, revealing differentiate patterns of individual subjective QoL perception.

The main methods of the research are descriptive statistical analysis, ANOVA test of equality of variable means, and linear regression based statistical modelling. The empirical research is carried out exploring the European Social Survey (ESS), round 6, 2013, data, with the case of Lithuania considered.

Practical implications. Differentiate models, proved by statistical analysis and based on individual subjective and objective QoL factors, linking local place objective living conditions and subjective QoL perceptions in different socio-economic settings would help anticipate relevant policy measures. Those would act as instruments, increasing individual subjectively perceived QoL. Scientifically grounded ways to predict QoL perceptions and policy measures for respective changes in local places are useful for local place decision makers in socio-economic development, specifically, for policy representatives and other stakeholders.

\section{The Complex of Individual Subjectively Per- ceived QoL Factors in Local Places}

There have been three major philosophical approaches in defining QoL (Diener \& Suh, 1997). The first approach describes the characteristics of good life, dictated by normative ideals, based on religious, philosophical, or other cultural normative systems. The second approach has been based on the satisfaction of preferences: people would select the things that enhance their living most. Thus, in this tradition, the definition of the QoL of society relates to whether the citizens can obtain the things they desire (McCrea, Shyy, \& Stimson, 2014). The third approach to QoL has been based on experience: if a person experiences his / her life as good and desirable, it is assumed to be so. The feelings of joy, pleasure, contentment and satisfaction with life indicators are paramount (Diener \& Suh, 1997).

This research builds on a conceptual combination of all the three above-mentioned approaches. It states that QoL in a local place depends on appropriate socio-economic characteristics of a local place (normative approach) that provide residents with opportunities to choose and thus create respective objective life conditions (satisfaction of preferences based approach). These objective individual factors constitute the background for individual's subjective perception of the QoL (subjective experience based QoL).

The definitions of Quality and QoL (Feneri, Vagiona, \& Karanikolas, 2013; McCrea et al., 2006) include both objective and subjective sides of the phenomenon. QoL in a local place is about enabling local people (by objectively measured means), as far as possible, to attain their own goals - some specific aspirations, driven by human being's self-interests (the degree of the current goal attainment is measured by subjectively evaluated terms).

A range of concepts and theories as well as empirical research based evidence could be used to ground the expected causal relationships between objective and subjective QoL factors (external and internal ones) and the ultimate individually perceived QoL. The access to public funds, services and local facilities approach (Albouy \& Lue, 2015; CuadradoBallesteros, Mordan, \& Garcia-Sanchez, 2014), optimum centrality theory (Gupta, 2014), urban density and overloading, natural environments (Ietto, Salvo, \& Cantasano, 2014; Swindal, 2013), social (dis)organization theory, subculture theory (Rezvani \& Mansourian, 2011), residential location and community development theories (Kahn, 2013), etc., 
(McCrea, Marans, Stimson, \& Western, 2011; McCrea et al., 2011) could be mentioned. The choice of certain theories and conceptual justifications to support particular research would be subject to empirical data availability, respective structure of a statistical model and aims of certain research and statistical testing based modelling.

The objective and the external to the individual side of the QoL in a local place would be measured by a broad range of social indicators. Those can be defined as the measures of social well-being, providing a contemporary view of socioeconomic conditions. They monitor trends in a range of areas of a local place related concern over time. They are the statistics, reflecting socio-economic conditions and facilitating the process of assessing those conditions as well as their evolution. The primary function of social indicators may be regarded as the measurement of levels, distributions and changes in individual and societal welfare (Diener \& Suh, 1997; Feneri et al., 2013; Henchoz et al., 2015; Noll, 2002; Pukeliene \& Starkauskiene, 2011; Starkauskiene, 2011). Social indicators are the measures, not related to individuals or private households; they are the averaged objective measures, describing general macro level opportunities.

Considering the individual subjective side, the QoL is seen as a broad term encompassing the notions of a good life, a valued life, a satisfying life, and a happy life (Diener \& Suh, 1997; Feneri et al., 2013; Henchoz et al., 2015; Scogin, Morthland, DiNapoli, LaRocca, \& Chaplin, 2016). The concepts of a satisfying life and a happy life could be combined into the subjective well-being (McCrea et al., 2006) or individually perceived / experienced subjective QoL. Subjective satisfaction with urban living occurs at different geographic levels (e.g., community, town, city, state and even a broader region).

Some former research (McCrea et al., 2006) provides support for generalized findings, stating that empirically observed correlations between local place's objective social indicators and individuals' life satisfaction are weak. According to empirical testing, objective, external to the individual, circumstances do not greatly influence subjectively perceived QoL. Such conclusions, however, could not be seen as absolute and broadly generalizable due to the above-mentioned methodological difficulties in correlating and testing the relationships among macro level objective and micro level subjective QoL indicators. These relationships could not be treated as direct, but should rather be seen and investigated as formed by some unique local place specific patterns, as hypothesised in the present research. The solution to this problem, suggested in the present research, is the recognition of subjective QoL perception patterns, common in different socio-economic settings, such as cities, towns, rural areas or other, describing how different individual QoL factors affect individual subjectively perceived QoL.

In order to explore and recognize the differentiate patterns of individual subjectively perceived QoL in a local place, a range of internal personal objective and subjective QoL factors as intervening variables should be taken into account (Cracolici, Giambona, \& Cuffaro, 2012). Objective socio-economic external to the individual QoL macro level factors (e.g., local services, health care system and infrastructure, education infrastructure, communal services, etc.) are being perceived and utilized by individuals through some internal subjective QoL perception pattern, composed of personal or household specific variables (e.g., total income, individual health conditions, level of attained education, dwelling conditions, age, gender, etc.). Subjective macro level cultural and tradition-related factors, such as individualism / collectivism (Diener \& Suh, 1997), the feeling of inclusion and belonging, social fairness, etc., also account for some additional amount of variation in individual subjectively perceived QoL in a local place (McCrea et al., 2006; Tomaszewski \& Perales, 2014). These patterns of subjective QoL perception are the main object of the present research. It is expected and hypothesised that these patterns are different in varied socio-economic settings, and they are common and specific at the social community level.

External conditions in a local place influence, or even determine, to some extent, personal objective and subjective QoL factors (Figure 1) - intervening variables, analysed and measured at the micro individual level. Consequently, those form individual subjectively perceived QoL patterns. External factors are not directly related to particular persons and the ones impacting whole society. So, these relationships are difficult to explore and evaluate. However, these impacts differ from person to person and are determined by personal $o b$ jective and subjective QoL factors as well as individual personal socio-demographic characteristics, such as income, age, gender, cultural and moral values (Cracolici et al., 2012; Ferriss, 2006; Turksever \& Atalik, 2001), i.e., by a range of personal intervening variables.

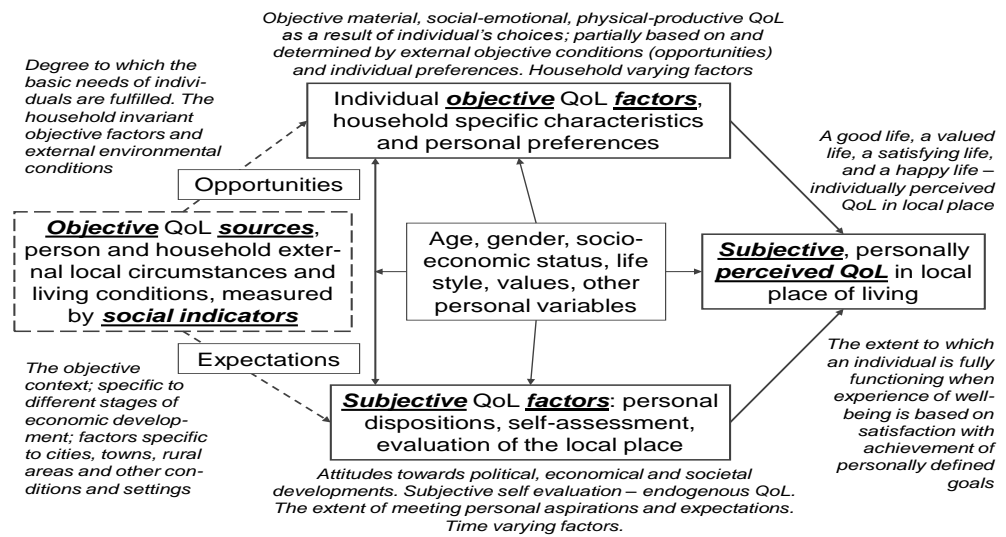

Figure 1. Conceptualization of the Expected Relationships Building Individual Subjectively Perceived QoL in a Local Place 
A study, based on the primary data from poor localities in Central Peru (Copestake, Guillen-Royo, Chou, Hinks, \& Velazco, 2009), has found out that people are generally happier in rural areas even though the poverty, in incidence, is greater there. Research has shown that rural respondents (facing lower objective QoL) are more satisfied with their living place and the progress in raising a family. However, those in urban areas have higher material QoL and the related aspirations which they find hard to fulfil. There is more scientifically proved evidence showing that most residents are satisfied with the place where they live because they choose local areas which satisfy them on objective attributes important to them, within the constraints they face (McCrea et al., 2014).

To summarize the theoretical argument above, Figure 1 is to show that the investigation of QoL in a local place encompasses all the three above-mentioned conceptual QoL perspectives. Local residents are economically and emotionally rational and they try to select the best possible place for living.

When judging subjective satisfaction (and, consequently, gaining personal subjective QoL factors), people perform evaluative assessment in which they compare their objective situation (e.g. their salary, their relationship with a neighbour, or their housing conditions) with an imagined ideal situation that they expect or aspire to attain (Tomaszewski \& Perales, 2014) in some specific local place. The closer their subjectively experienced conditions are to their imaginations, aspirations and / or expectations, the higher their rating of satisfaction will be, the more positive subjective QoL factors will be gained (Copestake et al., 2009). The relationship between local place specific external objective and individual internal subjective QoL indicators is complicated and not straightforward, thus, complex in predicting.

\section{The Research Method to Reveal Local Place Spe- cific Differentiate Patterns of Subjectively Per- ceived QoL}

The further empirical analysis is aimed at investigating interdependencies among individual objective and subjective QoL factors as well as personal socio-demographic characteristics and ultimate individual subjectively perceived QoL at the municipal / local place level, using micro individual survey data. The observed relationships will be tested in separate samples of big cities, towns and rural areas - environments, representing different external local place specific QoL related socio-economic conditions. The characteristics of local places are described by selected macro level social indicators. The tested interdependencies are observed at the micro personal / individual level and investigated by means of linear regression statistical analysis.

Though social indicators are a common source of data in QoL research (Diener \& Suh, 1997), the regression modelling based analysis requires that the observed cases (i.e. residents, individuals) are described by all dependent and independent indicators, further included in the models. Social indicators provide averaged data, so they are not appropriate for regression analysis (Clogg, Petkova, \& Haritou, 1995; Meyers, Gamst, \& Guarinou, 2013). Social indicators provide relevant data to define the local context, local external conditions and factors which may determine possibilities to have respective objective QoL.

Since it is not possible to statistically analyse the relationships between external local conditions and individual QoL factors, based on them, at the micro individual level (Clogg et al., 1995; Meyers et al., 2013), the analysis could consider several parallel models, representing differentiate patterns of subjective individually perceived QoL, based on objective and subjective personal QoL factors using the data of samples from different socio-economical settings. It is expected that individual subjectively perceived QoL $\left(Q o L_{s u b j}\right)$ in a local place depends on, or could be influenced by, objective $\left(F_{o b j}\right)$ and subjective $\left(F_{\text {subj }}\right)$ individual QoL factors as well as personal objective socio-demographic characteristics $(P)$ :

$$
Q o L_{s u b j}=f\left(F_{O b j} ; F_{s u b j} ; P ; e\right)
$$

The research aims at revealing and proving differences in the above-stated function (Eq. 1) of individually perceived subjective QoL in different socio-economic settings that are specific to big cities, towns and rural areas. Similar (in terms of the included parameters) regression models are further explored, using the data of the city, town and rural area samples. These different regression models, if proved statistically significant and significantly different, could be used to simulate the expected changes of individual subjectively perceived QoL, using exact model parameters, relevant to a certain development strategy.

In operationalized regression models, $F_{o b j}$ variables encompass objective QoL factors: personal characteristics, such as income, the level of education, objective health status and other. Those factors are, in part, subject to personal choice and respective life strategies, but could be also partially determined by external environmental conditions, i.e., objective QoL in local place specific opportunities. A set of $F_{\text {subj }}$ independent variables could include subjective evaluation of certain QoL domains, personal aspirations and expectations regarding external circumstances and objective QoL factors (as noted in the previous section).

Subjective evaluations, aspirations and expectations personal subjective QoL factors ( $F_{s u b j}$ model variables) could be partially explained by the expected impacts of sociodemographic characteristics of particular individuality (i.e., gender, ethnicity and social status) and time period (i.e., age, employment, etc.) specific $(P)$ variables (Tomaszewski \& Perales, 2014). Entire households could also have distinct properties and characteristics which make their inhabitants particularly happy / satisfied or unhappy / unsatisfied with living in a local place. These may include factors, such as size, quality and appropriateness of the physical environment, geographical location, and neighbourhood characteristics - i.e., many of already mentioned objective QoL in a local place factors - which should be common to all individuals, living together (Tomaszewski \& Perales, 2014).

The above-reasoned conceptual model of individually perceived subjective QoL can be transformed, [with] the common equation representing the expected causal interdependency:

$$
Q o L_{s u b j}=\beta_{1} F_{O b j}+\beta_{2} F_{s u b j}+\beta_{3} P+e
$$

Figure 2 summarizes the steps of empirical research to reveal local place specific differentiate patterns of individual 
subjectively perceived QoL. This strategy is applied to investigate the expected differences in the case of Lithuania's big cities, towns and rural areas. First, the difference of the objectively measured QoL $\left(Q o L_{o b j}\right)$ in various local places should be reasoned and justified. To do so, a set of social indicators should be selected and compared by the means of descriptive analysis. Next, the appropriate empirical indicators should be chosen to describe personal objective and subjective QoL related factors $\left(F_{s u b j}, F_{o b j}\right)$, building individual subjectively perceived QoL patterns.

\begin{tabular}{|c|}
\hline $\begin{array}{l}\text { escriptive analyses of the selected social indicators }\left(Q o L_{o b j}\right) \text { proving expected } \\
\text { differences of patterns of subjectively perceived } Q \mathrm{oL}, \text { when objectively } \\
\text { measured conditions in different local places differ, while subjective } \mathrm{QoL} \\
\text { perceptions remains similar or differ in other ways than objective factors }\end{array}$ \\
\hline \\
\hline $\begin{array}{l}\text { Theoretical reasoning of the model and its operationalization by selecting varia- } \\
\text { bles to depict objective and subjective personal } \mathrm{QoL} \text { factors }\left(F_{\text {subj, }} F_{\text {obj }}\right) \text {, socio- } \\
\text { demographic predictors }(P) \text {, individual subjectively perceived } \mathrm{QoL}\left(\mathrm{QoL}_{\text {subj }}\right)\end{array}$ \\
\hline 5 \\
\hline $\begin{array}{l}\text { Statistical testing of observed predictors differences; } \text { indicators with statistically } \\
\text { equal average values (means) across samples are expected to reveal } \\
\text { differences in patterns of individual subjective QoL perceptions }\end{array}$ \\
\hline$\sum$ \\
\hline $\begin{array}{l}\text { Regression analyses based modelling of } \\
\text { ceived QoL in local places; regression co } \\
\text { tors are considered as ones revealing } \\
\end{array}$ \\
\hline
\end{tabular}

Figure 2. The Process of Empirical Research, Revealing Local Place Specific Differentiate Patterns of Subjectively Perceived QoL

Then, personal factors (objective and subjective), included in the model, should be tested for mean value differences in all the investigated samples. When means values differences are considered to be statistically not significant (i.e., the hypothesis that mean values are not differentiate across samples is accepted), the effect (represented by regression model coefficients) of respective factor will be attributed to local place characteristics. However, if mean values of certain factor $\left(F_{s u b j}\right.$, or $\left.F_{o b j}\right)$ variables are statistically significantly different across the investigated samples, this difference should be considered in modelling and predicting the expected individual subjective QoL perception; only a part of the effect could be attributed to the objective external characteristics whereas the remaining effect should be associated with factor value differences themselves.

Statistically proved patterns, derived by the means of statistical linear regression analysis, would describe how different objective external local place specific QoL factors are translated into individual subjectively perceived local place related QoL $\left(Q o L_{s u b j}\right)$. Finally, statistical regression models are to be tested for significance of its difference.

\section{QoL in Lithuanian Cities, Town and Rural Ar- eas, Measured by Social Indicators (Year of 2013 Data)}

To reason the difference of objective socio-economic conditions as external QoL factors in different local places, common social indicators data is compared. Statistics Lithuania (http://www.stat.gov.lt/en/home) provide data on

\footnotetext{
1 Includes resident in largest Lithuania cities: Vilnius, Kaunas, Klaipėda, Šiauliai, and Panevėžys.

2 In points, from 0 (completely dissatisfied) to 10 (completely satisfied).
}

monthly disposable income in cash per household (Table 1), average subjective satisfaction (Table 2) and educational attainment (Table 3) in Lithuania's big cities, towns and rural areas.

Table 1

Monthly disposable income in cash per household, EUR, 2013 (Statistics Lithuania, http://www.stat.gov.lt/en/)

\begin{tabular}{|l|l|r|}
\hline No. & \multicolumn{1}{|c|}{ Type of the local place } & EUR \\
\hline 1. & Big cities $^{1}$ & 845.2 \\
\hline 2. & Other cities, towns & 665.6 \\
\hline 3, & Rural areas & 636.9 \\
\hline
\end{tabular}

It can be concluded that, objectively, QoL in different local places varies. A direct and narrow conceptual approach based inference suggests that, according to the fact that objectively measured QoL in big cities is about 30\% higher, compared to other towns and rural areas, a respective similarity could be also expected in subjectively perceived QoL. However, as shown in Table 2, subjectively and at the micro individual level measured QoL does not differ, as expected. In the context considered here, the indicator of overall satisfaction with the present life should be used as an indicator, reflecting objective and subjective personal living conditions. Its value is almost equal. Evaluation and satisfaction with household's financial situation as well as satisfaction with a living environment could be used as indicators describing personal subjective QoL factors which could be included in the regression model, depicting the patterns of overall subjective QoL perception.

Table 2

Average Satisfaction of Persons Aged 16 and Older With Various Aspects of Life ${ }^{2}, 2013$ http://www.stat.gov.lt/en/)

\begin{tabular}{|c|l|c|c|c|}
\hline No. & $\begin{array}{c}\text { Type of the local } \\
\text { place }\end{array}$ & $\begin{array}{c}\text { Present } \\
\text { life }\end{array}$ & $\begin{array}{c}\text { Household's } \\
\text { fin. situation }\end{array}$ & $\begin{array}{c}\text { Living } \\
\text { envirm. }\end{array}$ \\
\hline 1. & Big cities & 6.8 & 5.9 & 8.1 \\
\hline 2. & Other cities, towns & 6.7 & 5.7 & 8.6 \\
\hline 3. & Rural areas & 6.7 & 5.8 & 6.9 \\
\hline
\end{tabular}

Differences in the population structure by the level of education (Table 3) suggest that the indicator of average education level also could be relevant when investigating different patterns in QoL perception in different socio-economic settings, since population structure by education differs significantly in urban and rural areas. It also explains the existing differences in external QoL conditions.

Table 3

Educational Attainment of the Population, 15 and More Year Old, 2013, http://www.stat.gov.lt/en/)

\begin{tabular}{|c|l|c|c|c|c|}
\hline No. & \multicolumn{1}{|c|}{ Education $^{\mathbf{3}}$} & \multicolumn{2}{c|}{ Urban areas } & \multicolumn{2}{c|}{ Rural areas } \\
\hline & & thousand & percent & thousand & percent \\
\hline 1. & Higher & 558.4 & 33.0 & 110.1 & 13.2 \\
\hline 2. & Vocational & 557.0 & 32.9 & 313.0 & 37.6 \\
\hline 3. & General & 171.7 & 10.1 & 145.9 & 17.5 \\
\hline 4. & Primary & 120.2 & 7.1 & 120.3 & 14.5 \\
\hline 5. & Special & 287.2 & 16.9 & 142.5 & 17.1 \\
\hline & Total & $\mathbf{1 6 9 4 . 5}$ & $\mathbf{1 0 0 . 0}$ & $\mathbf{8 3 1 . 8}$ & $\mathbf{1 0 0 . 0}$ \\
\hline
\end{tabular}

3 Higher - Higher, professional colleges; Vocational - Vocational upper secondary, general upper secondary, vocational lower secondary; General - General lower secondary, vocational qualification without completion of lower secondary; Special - Special upper secondary, vocational post-secondary. 
The data provided above is sufficient to conclude that QoL, measured by objective external indicators, differs in different local areas. This difference does not correspond to the differences of subjectively evaluated QoL, measured as individual satisfaction with the present life (Table 2). This conclusion supports a general hypothesis and the expectation tested in the present research. It means that some pattern or a latent mechanism of subjective QoL perception, governing evaluations and weightings that are used by individuals, is different in different local places.

\section{Differences of Subjectively Perceived QoL in Lo- cal Places: Model Reasoning, Analysis, Results Based on the European Social Survey Data}

Theoretically expected relationships among QoL factors and outcomes are operationalized by selecting several personal objective and subjective QoL factors manifesting indicators and one variable, describing individually perceived subjective QoL as an outcome.

To demonstrate and investigate the relations between subjectively perceived QoL and personal objective as well subjective QoL factors across Lithuanian municipalities, averaged in the samples of big cities, towns and rural areas, the European Social Survey (ESS) round 6, completed in 2013, (http://www.europeansocialsurvey.org/) data is further used.

A conceptual background for independent variable selection reasoning has come from the above-cited previous research in the field of QoL in a local place. Income level and respective amount of assets owned by local residents depend, to some extent, on the local place of living and socio-economic condition based opportunities, provided here for local residents. The income level is treated as one of the individual objective QoL factors, related to the context of local places. Given the fact that income and asset ownership has multiple positive impacts (e.g. the promotion of household stability, enhancement of future orientation, increase of self-efficacy, self-esteem, etc.), it is assumed (Ferriss, 2006; Hong \& Han, 2014) that income and economic assets may enhance life satisfaction and thus individual subjective QoL perception. Economic assets enhance the feeling of financial security. Financial security, therefore, can increase positive perceptions of life as a whole. Table 4 explains the selected variables in detail, providing information on the exact wording of the questionnaire questions and answer scales, used in the European Social Survey.

In the tested model, a personal objective QoL factor is represented by the household total net income ('hinctnta') variable, while the subjective material status evaluation is measured by an opinion on the ability to deal with important problems in life ('deaimpp') variable. It is expected that the ability to deal with important problems in life is being determined by persons' education, health conditions and other objective personal QoL factors, including household income, measured by separate objectively evaluated indicators. The 'deaimpp' variable is originally coded as ordinal. However, since more than seven categories are used in the regression model, this ordinal variable is treated as a scale variable

\footnotetext{
1 Policy and Public Administration Institute at Kaunas University of Technology. (2014). ESS6, main and supplementary questionnaire
}

(Clogg et al., 1995; Meyers et al., 2013; Paternoster, Brame, Mazerolle, \& Piquero, 1998).

Table 4

Initial Variables of the Regression Model Based on European Social Survey (round 6) Data ${ }^{1}$

\begin{tabular}{|c|l|l|l|}
\hline No. & Name & Label, survey question & \multicolumn{1}{|c|}{ Scale } \\
\hline 1. & ppltrst & $\begin{array}{l}\text { Most people can be } \\
\text { trusted or you can't be } \\
\text { too careful }\end{array}$ & $\begin{array}{l}\text { 0 - You can't be too careful } \\
\ldots 10 \text { - Most people can be } \\
\text { trusted }\end{array}$ \\
\hline 2. & pplfair & $\begin{array}{l}\text { Most people try to take } \\
\text { advantage of you, or try } \\
\text { to be fair }\end{array}$ & $\begin{array}{l}\text { 0 - Most people try to take } \\
\text { advantage of me ... 10 - Most } \\
\text { people try to be fair }\end{array}$ \\
\hline 3. & pplhlp & $\begin{array}{l}\text { Most of the time people } \\
\text { helpful or mostly looking } \\
\text { out for themselves }\end{array}$ & $\begin{array}{l}\text { 0 - People mostly look out for } \\
\text { themselves ... 10 - People } \\
\text { mostly try to be helpful }\end{array}$ \\
\hline 4. & deaimpp & $\begin{array}{l}\text { Deal with important } \\
\text { problems in life }\end{array}$ & $\begin{array}{l}\text { 0 - Extremely difficult ... 10 - } \\
\text { Extremely easy }\end{array}$ \\
\hline 6. & hinctnta & $\begin{array}{l}\text { Household's total net in- } \\
\text { come, all sources }\end{array}$ & $\begin{array}{l}10 \text { categories starting from } \\
\text { below 700 and ending with } \\
\text { above 3000 Litas }\end{array}$ \\
\hline 7. & agea & $\begin{array}{l}\text { Age of respondent, cal- } \\
\text { culated }\end{array}$ & $\begin{array}{l}\text { Years of full-time educa- } \\
\text { tion completed }\end{array}$ \\
\hline 8. & stflife & $\begin{array}{l}\text { How satisfied with life as } \\
\text { a whole }\end{array}$ & $\begin{array}{l}\text { 0 - Extremely dissatisfied ... } \\
10 \text { - Extremely satisfied }\end{array}$ \\
\hline 9. & happy & How happy are you & $\begin{array}{l}\text { 0 - Extremely unhappy ... 10 } \\
\text { - Extremely happy }\end{array}$ \\
\hline
\end{tabular}

A demographic and social structure of a community / society provides the basis for interactions that lead to satisfaction, subjective well-being and the overall subjectively perceived QoL in a local place (Ferriss, 2006). The social structure may be considered in terms of socio-demographic characteristics of society, institutional composition, culture patterns and social psychological milieu of the community / society. Individual's interaction within the community is determined by the vitality of its formal and informal institutional structure and by one's degree of interaction within it. Vitality refers to the level of activity within the institution, such as the frequency of members gathering together, the interest and involvement of members, etc. Established cultural patterns also affect participation (Ferriss, 2006; McCrea et al., 2006).

In order to include the evaluations of local place community qualities as a personal subjective QoL factor variable into the tested model, three indicators are used. As explained in Table 4, these subjective evaluations include respondents' attitudes to trust, fairness and helpfulness of local place residents ('ppltrst', 'pplfair' and 'pplhlp').

An independent variable 'soc_trst_fair_hlp' is a calculated average of three variables that are used to investigate respondent's attitude to the social environment they live in ('ppltrst', 'pplfair' and 'pplhlp' original variables are used to calculate averaged index values of the 'soc_trst_fair_hlp' variable). The reasoning for building and using the averaged independent 'soc_trst_fair_hlp' variable is based on the fact that all these three variables are used to measure very close aspects in the framework of QoL phenomena and they correlate among each other. The Pearson's correlation coefficient value for 'ppltrst' and 'pplfair' is 0.627 , for 'ppltrst' and 'pplhlp' it is 0.555 , and for 'pplfair' and 'pplhlp' it is 0.485 . These correlations are significant at the 0.01 level (2-tailed),

data, Lithuania, may - august 2013, edition 2. Retrieved from www.lidata.eu/ 
the number of valid cases exceeds 2000. Cronbach's alpha criteria value is 0.788 , which indicates a high level of internal consistency for these three variables. It is expected that several variables would describe a particular QoL aspect more smoothly and with higher confidence, adjusting biases, possible due to specific question wording and respondents' personal attitudes to certain terms.

Variables 'eduyrs' and 'agea' (Table 4) represent individual objective demographic characteristics (denoted by $P$ in the conceptual model) and preferences which in the present model are associated with respondents' age (variable 'agea') and the number of years of full time education completed (variable 'eduyrs'). Both of these variables are measured by numerical scales, so they are suitable for being included in regression models (Clogg et al., 1995; Meyers et al., 2013; Paternoster et al., 1998).

The dependent variable (named 'happy_stfied', Table 4), included in the tested regression model (Figure 3), is calculated as an average of two original variables data: 'stflife' describing how respondent is satisfied with life as a whole and 'happy' which was used to collect data about respondent's attitudes to theirs happiness. Both indicators are measured with the same number of numerically coded categories. The Pearson's correlation coefficient shows medium to strong correlation between these two variables. Correlation coefficient value is 0.739 , correlation is significant at the 0.01 level (2-tailed), total number of cases being 2045. Cronbach's alpha value is 0.847 , which indicates a high level of internal consistency for 'stflife' and 'happy' variables (values near or above 0.7 are considered as standard for a reasonable level of accepting internal consistency of an index indicator) (Clogg et al., 1995; Meyers et al., 2013; Paternoster et al., 1998).

However, the selection and reasoning of any set of variables and its usage is subject of a further scientific theoretical and methodological discussion. Some limitations in this research are also inescapable due to the fact that a different model, operationalized using a different set of certain indicators outcomes with different results.



Figure. 3. Operationalized Model of the Expected Impacts on Individual Subjectively Perceives QoL in Local Places

Table 5 provides descriptive statistics of all the selected variables operationalizing the investigated model of subjective individually perceived QoL.
Table 5

Descriptive Statistics of QoL Factors Variables in Samples of Big Cities, Towns and Rural Areas of Lithuania

\begin{tabular}{|l|c|c|c|c|c|c|c|c|c|}
\hline \multirow{2}{*}{$\begin{array}{l}\text { Variables } \\
\text { Names }\end{array}$} & \multicolumn{4}{|c|}{ Big city } & \multicolumn{3}{c|}{$\begin{array}{c}\text { Town or small } \\
\text { city }\end{array}$} & \multicolumn{3}{c|}{ Country village } \\
\cline { 2 - 10 } & $\mathbf{N}$ & Mean & $\begin{array}{l}\text { Std. } \\
\text { Dev }\end{array}$ & $\mathbf{N}$ & Mean & $\begin{array}{l}\text { Std. } \\
\text { Dev }\end{array}$ & N & Mean & $\begin{array}{l}\text { Std. } \\
\text { Dev }\end{array}$ \\
\hline $\begin{array}{l}\text { happy_stfie } \\
\text { d }\end{array}$ & 721 & 6.500 & 2.026 & 729 & 6.141 & 1.92 & 639 & 6.109 & 1.90 \\
\hline $\begin{array}{l}\text { soc_trst_fa } \\
\text { ir_hlp }\end{array}$ & 718 & 5.055 & 1.771 & 729 & 5.025 & 1.84 & 640 & 5.251 & 1.92 \\
\hline hinctnta & 613 & 7.34 & 2.66 & 580 & 5.90 & 2.86 & 526 & 5.76 & 2.78 \\
\hline eduyrs & 713 & 13.57 & 2.72 & 720 & 12.45 & 2.89 & 640 & 11.82 & 3.04 \\
\hline agea & 721 & 42.40 & 17.71 & 729 & 45.65 & 17.71 & 640 & 47.25 & 19.05 \\
\hline deaimpp & 709 & 5.65 & 2.08 & 719 & 5.66 & 1.96 & 627 & 5.63 & 1.82 \\
\hline Valid N & $\mathbf{5 9 6}$ & & & $\mathbf{5 6 2}$ & & & $\mathbf{5 1 8}$ & & \\
\hline
\end{tabular}

To statistically test the significance of differences of the means of variables, observed in several samples, two conditions should be satisfied: 1) variables data should be distributed normally; 2) variances of the compared variables must be homogeneous (Clogg et al., 1995; Field, 2009; Meyers et al., 2013; Paternoster et al., 1998). In all 18 tests (six variables in three samples) null hypotheses of Kolmogorov-Smirnov test for normality were rejected and it has been concluded that the distribution of variables is normal at the 0.05 level of statistical significance ( $p$ values of all tests were below 0.05 level).

The variance homogeneousness of the above reasoned dependent and independent variables have been tested with Levene Statistic and one way ANOVA. The variances of 'happy_stfied,' 'soc_trst_fair_hlp', 'eduyrs' and 'hinctnta' variables are considered homogeneous (Sig. > 0.05) among three samples. Thus, statistical analysis of means differences significance could be done correctly (the exact levels of tested variances homogeneousness are as follows: Sig. happy_stfied $=0.250$, Sig. soc_trst_fair_hlp $=0.053$, Sig. eduyrs $=0.594$, and Sig. hinctnta $=0.059$ ). Variances of 'deaimpp' and 'agea' variables are not homogeneous among city, town and rural area samples (in both cases significance level value was 0.002).

So, the 'deaimpp' variable will not be tested for means differences. This does not prevent from including the variable into regression models. But since the means of the variable are very close to each other in different samples (Table 5), it could be expected that this personal subjective QoL factor is perceived by individuals' relatively similarly and any effects onto the dependent variable, should be attributed to the place of living factor and the related objective external, local place specific, QoL factors, that are not measured directly at the micro individual level (as discussed above). On average, dealing with important problems in life is not differentiate among residents of big cities, town and rural areas in Lithuania; dealing with important problems in life is considered and perceived alike in different places.

Although descriptive statistics reflects some differences among mean value of respondents' age in different samples (Table 5), the variances are not homogeneous and statistical significance of mean differences of age in populations could not be proved. 
Finally, a One Way ANOVA (Field, 2009) analysis has been applied to test statistical significance of selected variables means differences in three independent samples and respective populations. Means of three out of four tested variables are significantly different among the three samples. Means of 'soc trst fair hlp' variable $(p=0.054>0.05)$ are not differentiate significantly This finding leads to another preliminary conclusion, based on statistical proving that residents in different socio-economic settings treat social trust, fairness and helpfulness alike despite the observed differences in descriptive statistics. Following the interpretation of estimated mean, equality is similar to the one, provided above, considering the 'deaimpp' variable and its means equality among different local place representing samples.

One Way ANOVA test has confirmed statistically significant means differences among the samples measuring subjectively perceived individual QoL ('happy_stfie) as a dependent output variable as well as objective individual QoL factors reflected in total years of education and total family income ('eduyrs' and 'hinctnta ' variables; $p=0.000<0.05$ ).

The validity of the hypothesised causal structure is stated due to (1) formal tests of adequacy between the model and empirical data, and (2) statistical significance of coefficients, provided that the model is uniquely identified. Causal hypotheses are confirmed to the extent to which the model fits the data (Russo, 2009). An indicator of the goodness of model fit is the coefficient of determination, which is defined as the squared coefficient of correlation $r$ and ranges between 0 and 1. The coefficient of determination is interpreted as the proportionate reduction of the total variation of $Y$ by means of the explanatory $X$ variables. Larger values of $R^{2}$ indicate that the $X s$ account for the total variation in $Y$ (Field, 2009; Russo, 2009).

Regression analysis has been done with separate samples data. In all the three instances, the 'eduyrs' variable has been found as the one least important in explaining change and predicting values of a dependent variable, i.e., individual subjective QoL in a local place perception. Since in two out of three compared samples the predictor was considered as not significant $(p>0.05$; towns sample $p=0.347$; rural areas sample $p$ $=0.402)$ in predicting dependent variable values, the 'eduyrs' variable was removed from further iterations of analysis trying to find most appropriate and comparable explanatory models.

The regression analysis, done using three different samples data and including the four above-discussed independent variables, has resulted in regression models capable to explain and predict individual subjectively perceived QoL, measured by the 'happy stfied' variable. According to the determination coefficient values, the most relevant has been the model based on the big city sample data; its $R^{2}$ value was 0.534 . The town and rural area data based models have shown lower $R^{2}$ values: 0.341 and 0.414 respectively. These values still are sufficient to prove the appropriateness of the identified regression models to predict, to some extent, the variance of the dependent 'happy_stfied' variable.

The collinearity statistics for independent variables confirm that independent variables do not correlate among each other and are relevant to explain the variance of a modelled dependent variable in all the three regression models. I.e., predictors correlate significantly with the depended modelled variable (the tolerance values are highly above 0 and near to 1) (Field, 2009). The normality of regression residuals distribution was estimated visually by estimating histogram charts. Based on the visual estimation, it has been concluded that residual values are distributed normally. Since samples are relatively big, some observed exclusions can not significantly impact the results of regression analysis.

Three different regression models, expected to justify differentiate patterns of individual subjectively perceived QoL in different local places, have been defined as the result of the above-described theoretical and respective empirical analysis. In Lithuania's biggest cities, towns and rural areas $Q o L_{s u b j}$, measured by the 'happy_stfied' variable (based on European Social Survey 2013 year data), could be predicted by the following models:

$\begin{array}{ll}\text { Lithuania sample } & \text { happy_stfied }=2.626+0.232 \cdot \text { soc_trst_fair_hlp }+0.165 \cdot \text { hinctnta }-0.017 \cdot \text { agea }+0.393 \cdot \text { deaimpp } \\ \text { Big cities } & \text { happy_stfied }=2.784+0.192 \cdot \text { soc_trst_fair_hlp }+0.159 \cdot \text { hinctnta }-0.026 \cdot \text { agea }+0.475 \cdot \text { deaimpp } \\ \text { Towns } & \text { happy_stfied }=3.088+0.205 \cdot \text { soc_trst_fair_hlp }+0.187 \cdot \text { hinctnta }-0.015 \cdot \text { agea }+0.297 \cdot \text { deaimpp } \\ \text { Rural areas } & \text { happy_stfied }=2.197+0.281 \cdot \text { soc_trst_fair_hlp }+0.139 \cdot \text { hinctnta }-0.011 \cdot \text { agea }+0.400 \cdot \text { deaimpp }\end{array}$

The analysis of independent variables mean differences has proved that within the set of four independent regression model variables only the mean of 'hinctnta' (i.e. one of objective personal QoL factors) is significantly different in the three investigated samples. Two indicators of personal subjective QoL factors - 'soc_trst fair hlp' and 'deaimpp' - are perceived alike across the samples. So, it could be expected that objective external factors in the place of living do not influence significantly the values (but not latent effect on dependent subjective QoL in local place perception) of these indicators. Such micro individual survey data based observations correspond directly to the social indicators, describing objective and subjective living conditions in different local places, provided by the statistics office (Tables 1 and 2).

Reflecting on the idea and aim of this research, it could be stated that household's total net income ('hinctnta') impacts a dependent variable partly by objectively observed dif- ference of income level among the three groups. A part of impact, however, could be also attributed to the latent individual subjective OoL perception patterns, represented by differentiate regression coefficients which control this particular predictor. The effects on a dependent variable of the remaining 'deaimpp', 'agea' and 'soc_trst_fair_hlp' predicting indicators are attributed to the effect of latent local place characteristics that are not measured directly by social survey based data and respective differentiate patterns of subjective QoL perception. This assumption is supported by the fact that means values of these variables are not significantly different across the three samples. 
The ANCOVA test should be applied in order to support this assumption (Field, 2009). The ANCOVA ${ }^{1}$ analysis (ANCOVA is short for Analysis of Covariance) examines the influence of an independent variable on a dependent variable while removing the effect of the covariate factor or factors. In the case of this particular analysis, an independent factor dividing the sample into three groups is the place of residence (with three categories) and covariate factors are 'soc_trst_fair_hlp', 'agea', and 'deaimpp' variables (excluding 'hinctnta' because its effect is attributed also to objective differences of means values across the samples) (Field, 2009). An ANCOVA is used to determine whether there are any statistically significant differences between the adjusted population means of three or more independent (unrelated) groups. If the difference exists, it is attributed to the effect of group characteristics.

ANCOVA first conducts a regression of independent variables (i.e. the covariates) on the dependent variable. The residuals (the unexplained variance in the regression model) are then subject to the ANOVA test. Thus, the ANCOVA tests whether the independent variable, or fixed factor (here place of residence), still influences the dependent variable (here 'happy_stfied') after the influence of the covariate(s) has been removed. If statistically significant influence of the factor is observed, then the conclusions about differentiate regression patterns in different samples (groups based on fixed factor variable) could be proved.

The ANCOVA test with 'happy_stfied' as a dependent variable, 'domicil' - as a fixed factor variable, and three predictors as covariates output with proving statistically significant differences of the dependent variable means among the three samples. The mean values of 'happy_stfied' after the impact of included covariates was removed are as follows: big cities - 6.616, towns - 6.204, rural areas -6.120 . ANCOVA analysis results provide the background to conclude that regression models' coefficients controlling 'soc_trst_fair_hlp', 'agea', and 'deaimpp' variables effects represent differentiate patterns of individual subjectively perceived QoL under different socio-economic conditions of big cities, towns and rural areas in Lithuania, because these factors are statistically equal across the samples, but regression coefficients and mean value of output variable differ.

\section{Discussion: Differentiate Patterns of Individual Subjectively Perceived QoL}

European Social Survey (2013, round 6) Lithuania sample data analysis has confirmed an often-reported observation, stating that different levels of objectively measured OoL do not correspond to the individual subjective OoL evaluations which often tend to remain equal despite the changing levels of objective conditions. Similar trends are also observed reviewing the QoL describing social indicators data, provided by Statistics Lithuania. Thus, the investigation of the latent patterns of individual subjectively perceived QoL seems to be a relevant scientific problem, worth an empirical research-based solution.

\footnotetext{
Statistics Solutions: Advancement Through Clarity. Conduct and Interpret One Way ANCOVA. https://www.statisticssolutions.com/oneway-ancova/
}

Accepting the revealed regression models as statistically significant and fitting the survey data, it would be reasonable to compare their coefficients, thus, discussing different patterns of individual subjective QoL perception in big cities, towns and rural areas. Considering the subjective evaluation of a local place environment (including respondent's average opinion about local peoples' helpfulness, fairness and trust to them), it has been observed that the change of this factor would have a higher effect on individual subjective QoL perception in rural areas, compared to big cities and towns. This means, rural area residents are more sensitive to social environments and social interactions. This assumption is supposed to be relevant, as social environment in rural areas is more close and personal.

Another subjectively evaluated independent QoL factor, included in the tested models, is residents' opinion about their ability to deal with important problems in life. This factor has been also evaluated equally across the three samples, but regression coefficients are different, indicating differentiate patterns of individual subjectively perceived QoL. On average, the evaluation of the ability to deal with important life problems in Lithuanian big cities, increased by 1 point, would add almost 0.5 point to an average subjectively perceived QoL, measured by the combined general satisfaction with life and happiness indicator. Among rural area residents, this effect would be 0.4 ; it is even smaller in towns -0.3 .

One of the guessed explanations could be based on the assumption that big city residents, having better objectively measured QoL conditions and dealing easily with important problems, tend to be more satisfied with life and happy because QoL here is objectively higher. Town and rural area residents value themselves as able to deal with life problems, but are less happy and less satisfied with life, because, measured objectively, the QoL in these local places is lower. This means that QoL related expectations are lower in the places where the objectively measured QoL is lower.

Respondent's age was only one personal socio-demographic indicator among the tested predictors of subjective QoL perception. A general conclusion can be drawn that an increased age results in lower satisfaction with life and overall individual subjectively perceived QoL. Differentiate patterns of the age effect have been also observed. On average, in the case of Lithuanian big cities, residents' age increased by 10 years would result in subjectively perceived QoL decrease by 0.26 point (in terms of 10 points dependent indicator variable measurement scale). In towns and rural areas this effect would be smaller, but also negative.

Household's total net income, representing objective QoL factors, was only one variable, statistically significantly different in big cities, towns and rural areas. Discussing coefficients differences, it could be noted that this particular objective QoL factor is most important in the local places, described as towns; here, the income change effect on individual subjectively perceived QoL would be most significant. Considering income change by rural area residents, they would react by the lowest change of subjectively perceived QoL. As already noted above, rural area residents value social environment instead of objective QoL factors. 
The present research is inevitably limited in terms of number of predictor variables and the explanatory power of models. Nevertheless, the scope of the research is expected to be broadened by applying the proposed methodology on different cases, aiming at finding differences and similarities of the revealed regression models, thus, allowing broader assumptions and generalization of the results.

\section{Conclusions}

Considering the former scientific research based and reported observations which state that individual subjectively perceived QoL influencing factors could constitute different patterns of QoL perception, probably, differing from place to place, the article explores methodological possibilities to model statistically probable cause-effect relationships between objective and subjective QoL factors as predictors and individual subjectively perceived QoL as a dependent outcome variable, established and empirically observed in Lithuania's big cities, towns and rural areas.

Scientific literature review based analysis has provided a conceptual assumption that QoL in a local place is influenced by a range of objective and subjective personal factors as well as some socio-demographic characteristics of residents. European Social Survey round 6 (2013) data has been used to operationalize a conceptual model. Variable variances and other descriptive characteristics have been tested, an operational model has been built, using the average satisfaction with life and happiness indicator as a dependent outcome variable as well as respondent's age, household's total income, ability to deal with important problems in life, and attitude to social environment (including trust, helpfulness and fairness of locals) as independent predictor variables. One supposedly-relevant indicator, a total number of years spent in various forms of education, has not proved as statistically significant, influencing individual subjectively perceived QoL.

Multiple linear regression analysis has resulted in revealing three statistically significant regression models that are able to explain 30-50 \% of individually perceived QoL indicator variance in Lithuanian big cities, towns and rural areas. Differentiate coefficients values of regression models coefficients are considered to be representing individual subjective QoL perception pattern differences.

Some main characteristics of the revealed individual subjective QoL in local place perception patterns follow. The most important factor in predicting and explaining individual subjective QoL in local place perception is the attitude towards the ability to deal with important problems in life. The attitude towards a local social environment is a more important factor in rural areas. An objective factor of material QoL - household's total net income - is most influential in local places, described as towns. Those and similar observations have been provided as the ones, justifying differentiate patterns of individual subjectively perceived QoL patterns in different local places.

\section{References}

Akranaviciute, D., \& Ruzevicius, J. (2007). Quality of life and its components' measurement. Inzinerine Ekonomika-Engineering Economics, 2(52), 44-49.

Albouy, D., \& Lue, B. (2015). Driving to opportunity: Local rents, wages, commuting, and sub-metropolitan quality of life. Journal of Urban Economics, 89, 74-92. https://doi.org/10.1016/j.jue.2015.03.003

Bruneckiene, J., Cincikaite, R., \& Kilijoniene, A. (2012). The specifics of measurement the urban competitiveness at the national and international level. Inzinerine Ekonomika-Engineering Economics, 23(3), 256-270. https://doi.org/ 10.5755/j01.ee.23.3.1272

Bruneckiene, J., Guzavicius, A., \& Cincikaite, R. (2010). Measurement of urban competitiveness in lithuania. Inzinerine Ekonomika-Engineering Economics, 21(5), 493-508.

Clogg, C. C., Petkova, E., \& Haritou, A. (1995). Statistical methods for comparing regression coefficients between models. American Journal of Sociology, 100(5), 1261-1293. doi:10.2307/2782277

Collins, B. (2013). Using a survey to estimate health expectancy and quality-adjusted life expectancy to assess inequali-ties in health and quality of life. Value in Health: The Journal of the International Society for Pharmacoeconomics and Outcomes Research, 16(4), 599-603. https://doi.org/10.1016/j.jval.2013.01.004

Copestake, J., Guillen-Royo, M., Chou, W., Hinks, T., \& Velazco, J. (2009). The relationship between economic and subjective wellbeing indicators in peru. Applied Research in Quality of Life, 4(2), 155-177. https://doi.org/10.1007/s11482009-9070-1

Cracolici, M., Giambona, F., \& Cuffaro, M. (2012). The determinants of subjective economic well-being: An analysis on italian-silc data. Applied Research in Quality of Life, 7(1), 17-47. https://doi.org/10.1007/s11482-011-9140-z

Cuadrado-Ballesteros, B., Mordan, N., \& Garcia-Sanchez, I. (2014). Is local financial health associated with citizens' quality of life? Social Indicators Research, 119(2), 559-580. https://doi.org/10.1007/s11205-013-0533-2

Diener, E., \& Suh, E. (1997). Measuring quality of life: Economic, social, and subjective indicators. Social Indicators Research, 40(1/2), 189-216. https://doi.org/10.1023/A:1006859511756

Feneri, A. M., Vagiona, D., \& Karanikolas, N. (2013). Measuring quality of life (QoL) in urban environment: An integrated approach. Proceedings of the 13th International Conference on Environmental Science and Technology.

Ferriss, A. L. (2006). A theory of social structure and the quality of life. Applied Research in Quality of Life, 1(1), 117-123. https://doi.org/10.1007/s11482-006-9003-1 
Gupta, S. (2014). Modeling regional disparities for a balanced quality of life and apportioning public funding: A graph theoretical approach. Applied Research in Quality of Life, 10(3), 473-493. https://doi.org/10.1007/s11482-014-9327-1

Henchoz, Y., Meylan, L., Goy, R., Guessous, I., Bula, C., Demont, M., . . Santos-Eggimann, B. (2015). Domains of importance to the quality of life of older people from two swiss regions. Age and Ageing, 44(6), 979-985. https://doi.org/10.1093/ageing/afv130

Hong, S., \& Han, C. (2014). Asset impacts on life satisfaction in an asset-rich country: Focusing on older adults in singapore. Social Indicators Research, 118(1), 125-140. https://doi.org/10.1007/s11205-013-0410-z

Ietto, F., Salvo, F., \& Cantasano, N. (2014). The quality of life conditioning with reference to the local environmental management: A pattern in bivona country (calabria, southern italy). Ocean \& Coastal Management, 102, Part A, $340-349$. https://doi.org/10.1016/j.ocecoaman.2014.10.014

Kahn, M. E. (2013). Local non-market quality of life dynamics in new wind farms communities. Energy Policy, 59, 800807. https://doi.org/10.1016/j.enpol.2013.04.037

Malkina-Pykh, I. G., \& Pykh, Y. A. (2008). Quality-of-life indicators at different scales: Theoretical background. Ecological Indicators, 8(6), 854-862. https://doi.org/10.1016/j.ecolind.2007.01.008

McCrea, R., Marans, R., Stimson, R., \& Western, J. (2011). Subjective measurement of quality of life using primary data collection and the analysis of survey data. In R. W. Marans, \& R. J. Stimson (Eds.), (pp. 55-75) Springer Netherlands. https://doi.org/10.1007/978-94-007-1742-8_3

McCrea, R., Shyy, T., \& Stimson, R. (2006). What is the strength of the link between objective and subjective indicators of urban quality of life? Applied Research in Quality of Life, 1(1), 79-96. https://doi.org/10.1007/s11482-006-9002-2


important. Social Indicators Research, 118(1), 87-101. https://doi.org/10.1007/s11205-013-0406-8

McCrea, R., Stimson, R., \& Marans, R. (2011). The evolution of integrative approaches to the analysis of quality of urban life. In R. W. Marans, \& R. J. Stimson (Eds.), (pp. 77-104) Springer Netherlands. https://doi.org/10.1007/978-94-0071742-8_4

Meyers, L. S., Gamst, G. C., \& Guarinou, A. J. (2013). Performing data analysis using IBM SPSS. New Jersey: Wiley.

Noll, H. H. (2002). Social indicators and quality of life research: Background, achievements and current TRends. In N. Genov (Ed.), Advances in sociological knowledge over half a century (). Paris: International Social Science Council.

Paternoster, R., Brame, R., Mazerolle, P., \& Piquero, A. (1998). Using the correct statistical test for the equality of Rregression Coefficients. Criminology, 36(4), 859-866. https://doi.org/10.1111/j.1745-9125.1998.tb01268.x

Przybyla, K., Kulczyk-Dynowska, A., \& Kachniarz, M. (2014). Quality of life in the regional capitals of poland. Journal of Economic Issues, 48(1), 181-196. https://doi.org/10.2753/JEI0021-3624480109

Pukeliene, V., \& Starkauskiene, V. (2011). Quality of life: Factors determining its measurement complexity. Inzinerine Ekonomika-Engineering Economics, 22(2). https://doi.org/10.5755/j01.ee.22.2.311

Rezvani, M. R., \& Mansourian, H. (2011). Developing small cities by promoting village to town and its effects on quality of life for the local residents. Social Indicators Research, 110(1), 147-170. https://doi.org/10.1007/s11205-011-9921-7

Russo, F. (2009). Causality and causal modelling in the social sciences: Measuring variations. London: Springer Science + Business Media B.V. https://doi.org/10.1007/978-1-4020-8817-9

Scogin, F., Morthland, M., DiNapoli, E. A., LaRocca, M., \& Chaplin, W. (2016). Pleasant events, hopelessness, and quality of life in rural older adults. The Journal of Rural Health, 32(1), 102-109. https://doi.org/10.1111/jrh.12130

Starkauskiene, V. (2011). Quality of life factors and its integrated measurement model (summary of doctoral dissertation)

Swindal, M. G. (2013). Towards sustainable rural regions in europe: Exploring inter-relationships between rural policies, farming, environment, demographics, regional economies and quality of life using system dynamics. Journal of Environmental Policy \& Planning, 15(1), 133-135. https://doi.org/10.1080/1523908X.2013.766482

Tomaszewski, W., \& Perales, F. (2014). Who settles for less? subjective dispositions, objective circumstances, and housing satisfaction. Social Indicators Research, 118(1), 181-203. https://doi.org/10.1007/s11205-013-0420-x

Turksever, A. N., \& Atalik, G. (2001). Possibilities and limitations for the measurement of the quality of life in urban areas. Social Indicators Research, 53(2), 163-187. https://doi.org/10.1023/A:1026512732318

Uysal, M., Sirgy, M. J., Woo, E., \& Kim, H. (. (2016). Quality of life (QOL) and well-being research in tourism. Tourism Management, 53, 244-261. https://doi.org/10.1016/j.tourman.2015.07.013

The article has been reviewed.

Received in April, 2016; accepted in December, 2016 